\title{
An Investigation on Injection Characteristics of Direct-Injected Heary Duty Diesel Engine by Means of Multi-Zone Spray Modeling
}

\author{
G. Javadi Rad ${ }^{1}$, M. Gorjiinst ${ }^{1}$, M. Keshavarz ${ }^{2}$, H. Safari ${ }^{3}$ and S.A. Jazayeri ${ }^{4}$ \\ 1 Noushirvani University of Technology, Babol, - Iran \\ 2 Iran Heavy Diesel Engine Mfg Co (DESA), Amol, - Iran \\ 3 University of Tehran, Teran, - Iran \\ 4 KN Toosi University of Tchnology, Teran, - Iran \\ e-mail: javadirad@gmail.com - gorii@nit.ac.ir - m.keshavarz@desa.ir - h.safari@gmail.com - jazayeri@kntu.ac.ir \\ * Corresponding author
}

Résumé - Étude sur les caractéristiques d'injection d'un moteur Diesel industriel à injection directe au moyen de la modélisation multi-zones de la pulvérisation. — Le but de cette étude est d'étudier l'effet des paramètres d'injection sur les caractéristiques de performance et d'émissions d'un moteur Diesel industriel. Afin d'analyser les caractéristiques d'injection et de pulvérisation du gazole assurées par un système d'injection "common-rail" haute pression, les paramètres d'injection tels que le calage de l'injection, la durée de l'injection, le taux d'injection et le nombre de trous de l'injecteur ont été étudiés en utilisant un modèle quasi-dimensionnel. Dans l'étude présentée, les performances et les émissions du moteur sont simulées à différents taux d'injection en faisant varier des paramètres d'injection. Enfin, la meilleure définition du système d'injection a été recherchée pour obtenir un moteur Diesel industriel avec un haut rendement et de basses émissions de NOx.

\footnotetext{
Abstract - An Investigation on Injection Characteristics of Direct-Injected Heavy Duty Diesel Engine by Means of Multi-Zone Spray Modeling - The purpose of this study is to investigate the effect of injection parameters on a heavy duty diesel engine performance and emission characteristics. In order to analyze the injection and spray characteristics of diesel fuel with employing high-pressure common-rail injection system, the injection characteristics such as injection delay, injection duration, and injection rate and number of nozzle holes were investigated by using a quasi-dimensional model. In the present work, the variety of injection rate is performed at various injection parameters where as performance and emission of the engine will be simulated subsequently. Finally the best injection system for a high efficiency and low $N O_{x}$ emission heavy duty diesel engine was investigated.
} 


\section{INTRODUCTION}

Nowadays, heavy duty diesel engines are the main sources of electrical power generation and marine propulsion as well as electrical power generation required for rail traction. Similar to other combustion engines, these engines are the main sources of Green House gasses and other pollutant emissions like NOx and PM. The higher thermal efficiency of the engine is the most important key for the market economy and it could reduce the amount of Green House gasses. However, higher thermal efficiency results in higher levels of $\mathrm{NO}_{x}$ emissions. On the other hand, the environmental regulations against diesel engines are becoming tighter year after year and these engines require further development to meet future standards for gaseous and particulate exhaust emissions [1]. These legislations should be achieved in line with high efficiency engine in order to decrease life cycle cost and exhaust emitted $\mathrm{CO}_{2}$ gases. Also the reliability and durability of the engine should be held on acceptable level [2]. In diesel engines mixture formation of fuel and air has a significant effect on the combustion and emissions, so that the injection technology became a key technology to control exhaust emission level. In order to produce smaller droplets and increase in the efficiency of the engine, nozzle hole size should be reduced. Also the injection pressure plays a significant role on both $\mathrm{NO}_{x}$ emission and thermal efficiency of the engine. In this study multiple set of injectors and injection strategies will be examined with common rail injection system to find the best configuration to achieve high efficiency and low $\mathrm{NO}_{x}$ engine concept. Multi-zone spray modeling is the efficient way to estimate DI diesel performance and emission and it is widely used in design and optimization of the engine. The good agreement of this model with experimental data made it a suitable way for studying the engine combustion characteristics. In the general frame of the design of new engine for railways, this study focused on various types of injectors and injection strategies with common rail injection. So, a multi-zone spray model is used to find combustion characteristic of a direct injected heavy duty diesel engine with a set of injector and injection strategies to find the best configuration for high efficiency and low $\mathrm{NO}_{x}$ engine concept.

\section{MULTI-ZONE SPRAY MODELING}

\subsection{Overview}

Multi-zone combustion model predicts the combustion rate and associated emissions for direct-injection diesel engines. This method was proposed by Hiroyasu et al. [3] for the first time and sometimes called by his name. At the first step of this model, the initial Sauter Mean Diameter (SMD) of the fuel parcels is derived from fuel injection rate and zone number. Then the air entrainment into each zone is
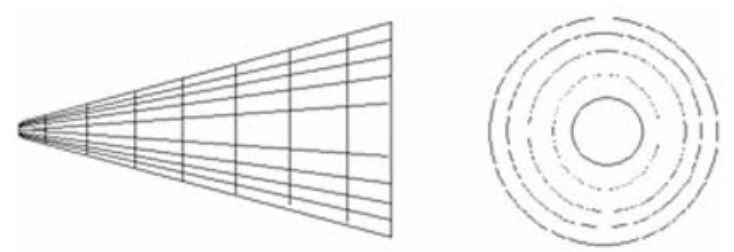

Figure 1

Schematic of the zone structure.

considered as well as fuel vaporization and the fuel-air mixture will be constructed. Finally, ignition and combustion will be calculated from mixing and fuel evaporation rate. The spray zones will be created in two directions: axial and radial. It means that liquid fuel is introduced into the domain by means of annular packages. Figure 1 shows the division of spray into zones at a certain time step.

It is assumed that there is no heat, mass and momentum transfer between the zones and that each annular section is subject to circumferential symmetry. Also because of the nature of heavy duty diesel engines, it is assumed that combustion chamber is quiescent, so that the effect of swirl on spray deflection can be neglected. The packages move forward so that they always remain in contact and cannot overtake one another. Individual zones experience their own history of temperature, pressure and composition. The total number of zones in the radial direction is fixed regardless of the amount of fuel injected or the time step used. The total number of zones in the axial direction is determined by the injection duration and the computational time step size [4].

\subsection{Fuel Injection Dynamics}

The fuel injected into the cylinder is initially assumed to form a liquid column that travels at a speed equal to the fuel injection speed until the fuel break-up time elapses. If it is assumed that the flow through each nozzle is quasi-steady, incompressible, and one dimensional, the mass flow rate of fuel injected through the nozzle, is given by [5]:

$$
\dot{m}=C_{D} A_{n} \sqrt{2 \rho_{l} \Delta P}
$$

Injection pressure is also determined by the fuel injection equipment supplier which is estimated from their hydraulic system simulation codes or tests. The discharge coefficient will be calculated from:

$$
C_{D}=\frac{1}{\sqrt{C_{i}+f \frac{L}{D}+1}}
$$

where $C_{i}$ is inlet loss coefficient, $f$ is friction coefficient, $L$ is nozzle length and $D$ is nozzle hole diameter. The friction 
coefficient will be calculated from:

$$
f=0.3164 R e^{-0.25}
$$

The above equation for $C_{D}$ is valid for the conditions in which no cavitation occurred. Because of cavitation effect in the nozzle, if the cavitation number is less than or equal to critical cavitation number, the discharge coefficient should be corrected as follows:

$$
C_{D}=\sqrt{\frac{K}{2.6874-11.4 \frac{R}{D}}}
$$

where $R$ is nozzle filet radius and $K$ is cavitation number and is calculated from:

$$
K=\frac{P_{i n j}-P_{v}}{\Delta P}
$$

where $P_{v}$ is the saturated vapor pressure of the fuel. The fuel injection velocity at the nozzle tip can be expressed as:

$$
u_{i}=C_{D} \sqrt{\frac{2 \Delta P}{\rho_{l}}}
$$

In the multi-zone model only the fuel spray is divided into a number of zones. The control volume of each zone is treated as an open system, and mass and energy equations are solved for each zone instead of solving the full momentum equation. Spray penetration before and after breakup will be calculated from [4]:

$$
\begin{array}{cc}
S=u_{i} t & 0<t<t_{b} \\
S=2.95 \sqrt{\left(\frac{\Delta P}{\rho_{a}}\right)^{0.5} D t} \quad t_{b} \leq t
\end{array}
$$

where breakup time, $t_{b}$, is:

$$
t_{b}=4.351 \frac{\rho_{l} D}{C_{D}^{2} \sqrt{\rho_{a} \Delta P}}
$$

In this study the best agreement between experimental and simulation results was achieved with the factor of 4.73 instead of 4.351 .

Reitz and Bracco [6] proposed the following correlation for spray angle:

$$
\theta=\arctan \left(\frac{4 \pi \sqrt{3 \frac{\rho_{a}}{\rho_{l}}}}{18+1.68 \frac{L}{D}}\right)
$$

The droplet size distribution within a zone, expressed in terms of the Sauter Mean Diameter (SMD). The Sauter Mean Diameter is expressed as the Volume of the droplet divided by its surface area. Because the droplets in each zone are distributed with different sizes, the SMD will be calculated from the following experimental expressions [7]:

$$
S M D=\max \left(S M D_{L S} ; S M D_{H S}\right)
$$

where

$$
\begin{aligned}
\frac{S M D_{L S}}{D} & =4.12 R e^{0.12} W e^{-0.75}\left(\frac{\mu_{l}}{\mu_{a}}\right)^{0.54}\left(\frac{\rho_{l}}{\rho_{a}}\right)^{0.18} \\
\frac{S M D_{H S}}{D} & =0.38 R e^{0.12} W e^{-0.75}\left(\frac{\mu_{l}}{\mu_{a}}\right)^{0.37}\left(\frac{\rho_{l}}{\rho_{a}}\right)^{-0.47}
\end{aligned}
$$

The number of drops in each zone can be determined knowing the SMD and the mass of fuel injected. Using an energy and mass balance for a single droplet in each zone, ordinary differential equations can be set up for the rate of change of the droplet temperature and diameter which is subsequently solved using a computational method.

\subsection{Air Entrainment and Evaporation}

The air entrainment rate into a given zone is controlled by the conservation of momentum applied to that zone. Therefore, the amount of entrained air of a zone is proportional to the decrement in the zone velocity:

$$
\dot{m}_{a e}=-C_{a e} m_{f} u_{i} \frac{\frac{d^{2} S}{d t^{2}}}{\left(\frac{d S}{d t}\right)^{2}}
$$

in which $C_{a e}$ is the air entrainment factor. This factor should be selected from the experiments, and it depends on engine speed, combustion chamber shape and injection specification. Because of quiescent nature of flow in heavy duty diesel engines, the effect of swirl on spray deflection will be ignored. With the assumption of uniform droplet temperature, the rate of droplet temperature change is determined by the energy balance equation, which states that the energy conducted to the droplet either heats up the droplet or supplies heat for vaporization. Therefore:

$$
m_{d} c_{p, d} \frac{d T_{d}}{d t}=Q_{L V} \frac{d m_{d}}{d t}+q_{h t}
$$

Convective heat transfer from the hot gas to liquid fuel droplets in a zone, $q_{h t}$, is modeled based on the following methodology which is simplified from the following equation [3]:

$$
q_{h t}=\pi d_{d} N k_{m}\left(T-T_{d}\right) N u
$$

where $N$ is the number of droplets which is derived from the amount of fuel injected into a zone, initial SMD of each zone and density of the liquid fuel, $T$ is the mean cylinder temperature, $k_{m}$ is mean thermal conductivity which could be defined by the partial pressure of the fuel vapor and air and their conductivities. The effects of boundary layer thickening due to mass transfer were not considered for simplicity in above equation. The rate of change in liquid droplet mass, $\frac{d m_{d}}{d t}$ is defined as [3]:

$$
\frac{d m_{d}}{d t}=-\pi d_{d} N D_{v a} S h \frac{2 P}{R_{v}\left(T+T_{d}\right)} \ln \left(\frac{P}{P-P_{v, s}}\right)
$$

where $D_{v a}$ is the binary mass diffusivity between fuel vapor and air, $R_{v}$ is the gas constant of the fuel vapor, $P_{v, s}$ is saturation pressure of fuel vapor at temperature of $T_{d}$. 
The Nusselt and Sherwood numbers are obtained from the following correlations [8]:

$$
\begin{aligned}
& N u=2+0.6 \operatorname{Re}_{d}^{0.5} \operatorname{Pr}^{0.33} \\
& S h=2+0.6 \operatorname{Re}_{d}^{0.5} S c^{0.33}
\end{aligned}
$$

The Reynolds, Prandtl and Schmidt numbers are defined from the thermodynamic properties of the mixture of fuel vapor and air at mean temperature of air and droplet temperature. Also the length scale for Reynolds number of the liquid droplet is its diameter.

The instantaneous mean diameter of droplets could be calculated from:

$$
d_{d}=\left[\frac{6\left(m_{d, i}+\int d m_{d}\right)}{\pi N \rho_{l}}\right]^{(0.33)}
$$

\subsection{Ignition Delay and Combustion}

Ignition delay will be calculated from the following simplified Arrhenius equation: [9]

$$
\tau_{d}=2 \times 10^{-2} P^{-0.25} \phi^{-1.04} \exp \left(\frac{4000}{T}\right)
$$

Ignition occurred when the following relationship is satisfied:

$$
\int_{0}^{\tau_{i g n}} \frac{d t}{\tau_{d, j}}=1
$$

The subscript " $j$ " denotes that ignition starts when the above relationship is satisfied once in a zone. Therefore, the equivalence ratio should be calculated in each zone with following expression:

$$
\phi_{j}=\frac{m_{i n j, j}-m_{d, j}}{f_{s t} m_{a, j}}
$$

where $m_{i n j, j}$ is the total fuel injected into zone $j, m_{d, j}$ is the instantaneous mass of liquid droplet in zone $j, f_{s t}$ is the stoichometric air-fuel ratio for the specified fuel, $m_{a, j}$ is the instantaneous entrained air into zone $j$.

The model proposed by Hiroyasu assumes that there is no single droplet surrounded by a flame and that the evaporated fuel reacts with the air entrained into the element forming a diffusion flame around a group of droplets. This model assumes that combustion occurs at stoichometric conditions and that some residual portion of fuel or air in the element participates in the next step of combustion.

Therefore, the burn rate for the $j$ th zone can be written as:

$$
\frac{d m_{b, j}}{d t}=\left\{\begin{array}{cc}
\frac{-d m_{d, j}}{d t} & \phi_{j} \leq 1 \\
\frac{1}{f_{s t}} \frac{d m_{a e, j}}{d t} & \phi_{j}>1
\end{array}\right.
$$

It is also stated in reference [4] that the premixed portion of the burn rate is controlled by following global rate of reaction:

$$
\frac{d m_{b, j}}{d t} \leq 5 \times 10^{5}\left(\rho_{m}^{2} x_{f, v}^{2} x_{a}^{2}\right)_{j} \exp \left(\frac{-1200}{T_{j}}\right) V_{j}
$$

where $x_{f, v}$ is mole fraction of fuel vapor in zone $j, x_{a}$ is mole fraction of air in zone $j$ and $V_{j}$ is the volume of $j$ th zone.

Also the global kinetic rate of diffusion combustion will be stated as:

$$
\frac{d m_{b, j}}{d t} \leq B m_{f v, j} \frac{P_{o x, j}}{P} P^{2.5} \exp \left(\frac{-2500}{T_{j}}\right)
$$

where $B$ is an experimental factor, $m_{f v, j}$ is the mass of fuel vapor in $j$ th zone and $P_{o x, j}$ is the partial pressure of oxygen in $j$ th zone.

So, the burn rate of the $j$ th zone, during diffusion burning phase, could be expressed by minimum value of equation (21) and (23) for diffusion and (23) for premixed combustion.

Local temperature of each zone could be calculated from the first law of thermodynamics. Because it is assumed that there is no heat, mass and momentum transfer between the zones, the first law of thermodynamics could be expressed as:

$$
m_{j} c_{p, j} \frac{d T_{j}}{d t}=\dot{H}+\frac{m_{a e, j}+m_{i n j, j}-m_{d, j}}{\rho_{m}} \frac{d P}{d t}-L H V \frac{d m_{b, j}}{d t}
$$

where:

$$
\dot{H}=-\dot{m}_{a e, j} h_{a}-m_{d, j} c_{p, d} \frac{d T_{d, j}}{d t}
$$

Volume of air zone will be calculated as:

$$
V_{a}=V-\sum \frac{m_{a e, j}+m_{i n j, j}-m_{d, j}}{\rho_{m}}
$$

So, the rate of pressure change in cylinder will be calculated from ideal gas law:

$$
\frac{d P}{d t}=m \frac{d\left(\frac{R T}{V}\right)}{d t}
$$

The rate of change of the air zone temperature could be derived from first law of thermodynamics for air zone:

$$
\begin{aligned}
m_{a} c_{p, a} \frac{d T_{a}}{d t}= & \sum_{j} \dot{m}_{a e, j} h_{a}-V_{a} \\
& +\sum_{j} \frac{m_{a e, j}+m_{i n j, j}-m_{d, j}}{\rho_{m}} \frac{d P}{d t}-q_{h t}
\end{aligned}
$$

where $q_{h t}$, is heat transfer between walls and in cylinder gasses which is defined by Woschni correlation and air zone temperature. The mean gas temperature will be calculated from:

$$
T=\frac{m_{a} c_{p, a} T_{a}+\sum_{j} m_{j} c_{p, j} T_{j}}{m_{a} c_{p, a}+\sum_{j} m_{j} c_{p, j}}
$$

In this study a software has been developed, to simulate full engine cycle such as pipe flow, intake, compression, expansion and exhaust gases. Only heat release calculations as mentioned above and emission estimation will be inserted as an external function for this software. Therefore, the equations and formulation for the rest of simulations are not presented here. 
TABLE 1

Specification of 16RK215 engine

\begin{tabular}{c|c|c}
\hline Bore $=215 \mathrm{~mm}$ & SOI $=-20$ ATDCF & Injection: Unit pump \\
\hline Stroke $=275 \mathrm{~mm}$ & Speed $=1000 \mathrm{RPM}$ & Fuel per shot $=1226 \mathrm{mg}$ \\
\hline Con-rod length $=502 \mathrm{~mm}$ & IVO $=303.5$ & Ambient: $20^{\circ} \mathrm{C}, 1 \mathrm{bar}$ \\
\hline $\mathrm{CR}=13.5: 1$ & $\mathrm{IVC}=-146.5$ & LT water temp. $=68^{\circ} \mathrm{C}$ \\
\hline Fuel: $\mathrm{C}_{13.5} \mathrm{H}_{27.6}$ & $\mathrm{EVO}=121.5$ & Nozzle config.: $8 \times 0.36 \mathrm{~mm}$ \\
\hline Engine Type: $D I-T C-I C$ & $\mathrm{EVC}=405.5$ & Inj. duration $=30^{\circ} \mathrm{CA}$ \\
\hline
\end{tabular}

\section{$1.5 \mathrm{NO}_{x} \&$ SOOT Emission Modeling}

The well-known extended Zeldovich mechanism is employed, that predicts the thermal contribution to $\mathrm{NO}_{x}$. Eleven chemical species are taken into consideration, namely: $\mathrm{CO}, \mathrm{CO}_{2}, \mathrm{O}_{2}, \mathrm{H}_{2}, \mathrm{H}_{2} \mathrm{O}, \mathrm{OH}, \mathrm{H}, \mathrm{O}, \mathrm{N}$ and $\mathrm{NO}$. Except for $\mathrm{NO}$ and $\mathrm{N}$ all other species are assumed to be in thermodynamic equilibrium. Soot is formed in the rich unburned-fuel-containing core of the fuel sprays and then is oxidized in the flame zone when it contacts unburned oxygen. The soot formation rate is calculated by assuming a first-order reaction of vaporized fuel as proposed by Hiroyasu et al. [3]:

$$
\begin{gathered}
\left(\frac{d m_{s, j}}{d t}\right)_{F}=A_{f}\left(m_{i n j, j}-m_{d, j}\right) P^{0.5} \exp \left(\frac{-E_{s f}}{R_{u} T_{j}}\right) \\
E_{s f}=1.25 \times 10^{4} \mathrm{kcal} / \mathrm{mol}
\end{gathered}
$$

$A_{f}$, is constant that are determined by experimental data. Soot oxidation model investigated in this study is the Nagle and Strickland-Constable oxidation model. The NSC oxidation model is based on oxidation experiments of carbon graphite in an $\mathrm{O}_{2}$ environment over a range of partial pressure. In this model, carbon oxidation occurs by two mechanisms whose rates oxidation occurs by two mechanisms whose rates A sites and less reactive B sites [4]. The chemical reactions are:

$$
\begin{aligned}
\mathrm{A}+\mathrm{O}_{2} & \longleftrightarrow \mathrm{A}+2 \mathrm{CO} \\
\mathrm{B}+\mathrm{O}_{2} & \longleftrightarrow \mathrm{B}+2 \mathrm{CO} \\
\mathrm{A} & \longleftrightarrow \mathrm{B}
\end{aligned}
$$

The soot oxidation rate will be calculated from:

$$
\left(\frac{d m_{s, j}}{d t}\right)_{\mathrm{O}}=\frac{M W_{\mathrm{C}}}{\rho_{s} d_{s}} m_{s, j} w
$$

Therefore,

$$
\frac{d m_{s, j}}{d t}=\left(\frac{d m_{s, j}}{d t}\right)_{\mathrm{F}}-\left(\frac{d m_{s, j}}{d t}\right)_{\mathrm{O}}
$$

where $M W_{\mathrm{C}}$ is molecular weight of carbon, $\rho_{s}$ is soot density $\left(2.0\right.$ g.cm $\left.{ }^{-3}\right), d_{s}$ is soot diameter $\left(4.5 \times 10^{-9} \mathrm{~m}\right)$, and $w$ is net reaction rate of proposed reactions mentioned above which is calculated from the method mentioned in Reference [4] and is not presented here.
TABLE 2

Comparison between experimental and simulation results for 16RK215 engine

\begin{tabular}{l|l|l}
\hline Parameter & Simulation & Experimental \\
\hline Brake power, $\mathrm{kW}$ & 2840 & 2844 \\
Maximum Cyl. Pressure, bar & 156 & 154 \\
Turbine inlet Temperature, ${ }^{\circ} \mathrm{C}$ & 607 & 555 \\
$T / C$ speed, min $^{-1}$ & 24262 & 25740 \\
Turbine outlet Temperature, ${ }^{\circ} \mathrm{C}$ & 377 & 342 \\
Exhaust mass flow rate, $\mathrm{kg} / \mathrm{s}$ & 5.027 & 6.191 \\
$\mathrm{NO}_{x}$ concentration, $\mathrm{ppm}$ & 914 & 1088 \\
\hline
\end{tabular}

\subsection{Model Validity}

We have used heavy duty diesel engine which is developed by MAN B\&W named RK215 for simulation. The specification of 16 cylinders RK215 which is tested in DESA and currently is used in Iranian Railways, are listed in Table 1. Table 2 and Figure 2 show the differences between experimental data and simulation results. These results show good agreement between simulation and experimental data.

\section{SIMULATION CASE DEFINITION}

Figure 3 shows the injection pressure which is proposed by FIE supplier for the standard common rail injection. It is fond that in order to have a good agreement between $\mathrm{NO}_{x}$ emission and fuel economy, the injection pressure would be 1600 bar. The FIE supplier declared that in order to achieve mean injection pressure of 1600 bar, the rail pressure should be about 1800 bar. Also because of the characteristics of high pressure common rail system for large engines, a high order overshoot in injection pressure will be created as shown in Figure 3

The FIE supplier proposed three type injectors with different number of holes and diameter, including 6, 7 and eight holes with discharge coefficient between 0.67 to 0.7 .

The length of the nozzle has been fixed to $1.15 \mathrm{~mm}$ by FIE supplier because of its strength integrity.

Also, the injection cone angle was selected with respect to injector/cylinder head design and optimized combustion chamber shape from the previous experiments of heavy duty diesel engines. 

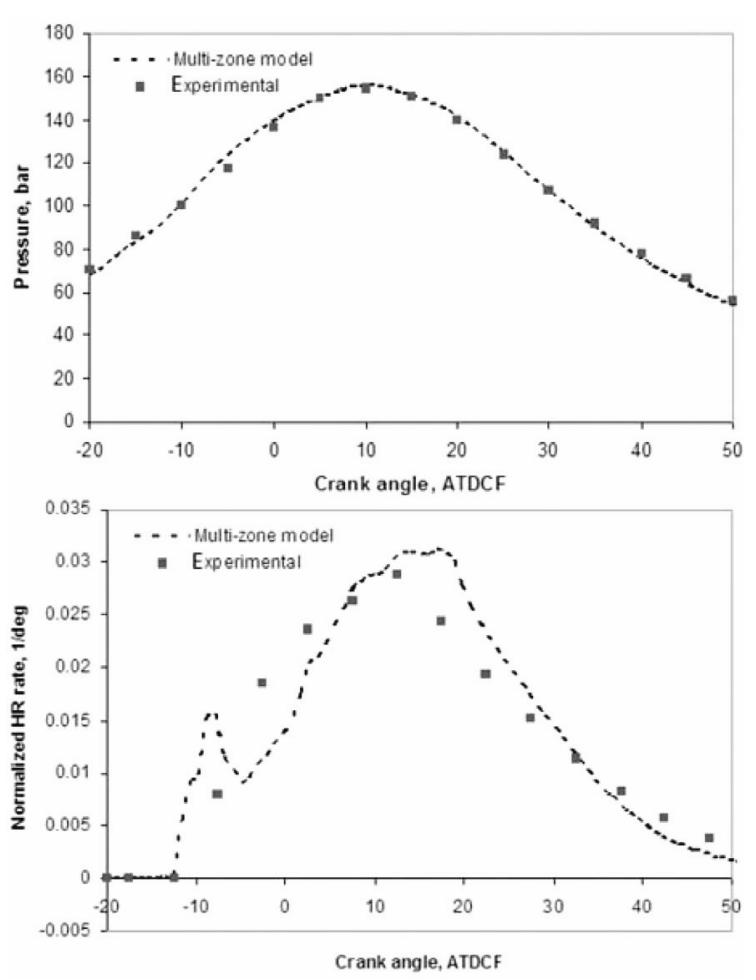

Figure 2

Comparison between experimental and simulation results for 16RK215.

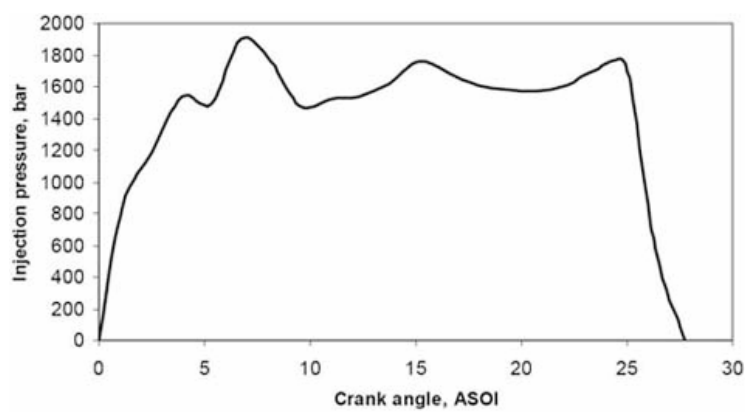

Figure 3

Injection pressure for standard common rail injection (6 hole nozzle).

The injection strategies with multiple injections were considered for the new engine. This strategy was defined with $5 \%$ and $10 \%$ pre-injection of diesel fuel. Another significant parameter in multiple injection strategy is dwell time is the time between pre-injection and main injection in which no fuel is injected into cylinder.

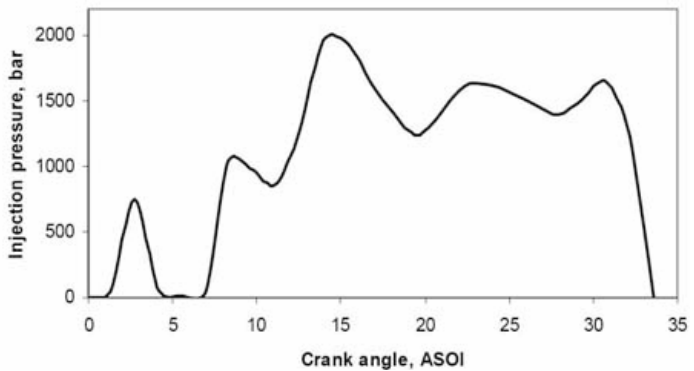

Figure 4

Injection pressure for 5\% pre-injected fuel (6 hole nozzle).

Figure 4 shows the injection pressure for the case with $5 \%$ pre-injection with 0.55 milliseconds dwell time.

The first simulation task is defined to find the best injection timing for each configuration. So the best injection timing will be achieved by compromizing between $\mathrm{NO}_{x}$ emission and fuel economy. So, with combination of three Nozzle types and injection strategies, pre-injection with different dwell time and standard with no pre-injection, a simulation matrix with multiple cases has been created and the simulation was started.

It shoud be noted that the main difference between 8 holes configuration and two others, is in the arrangement of the holes. There is a four set of holes distributed circumferential in each row for eight holes nozzle. This issue affects the injection duration and injection cone angle. Therefore, the injection duration of eight holes injector is different with two other configurations.

\section{SIMULATION RESULTS}

\subsection{A: In-Cylinder Results}

Firstly, two set of in-cylinder results will be presented here: cases 1, 3 and 6 for 6 holes injector and cases 15, 17 and 20 for 8 holes injector. The more information for the above cases are listed in Table 3.

Figure 5 show the liquid fuel mass in cylinder for set 1 and 2 of the results. These figures show that the major advantage of pre-injection is the decrease in the amount of fuel-air mixture just before the start of combustion.

This issue makes the mixture formation to be step by step during injection hence it avoids the large premix heat release at the first phase of combustion. Also pre-injection would cause the injection to start earlier than standard type for an approximately the same performance.

If we look at the heat release rate diagrams which is shown in Figure 6, the position will be clear. As shown in these figures, pre-injection splits pre-mixed heat release period and causes increase of the peak heat release rate at 
TABLE 3

Definition for the presented simulation cases

\begin{tabular}{|c|c|c|c|c|c|c|}
\hline Case & 1 & 3 & 6 & 15 & 17 & 20 \\
\hline Nozzle type & $\begin{array}{c}6 \times 0.29 \\
\mathrm{~mm}\end{array}$ & $\begin{array}{c}6 \times 0.29 \\
\mathrm{~mm}\end{array}$ & $\begin{array}{c}6 \times 0.29 \\
\mathrm{~mm}\end{array}$ & $\begin{array}{c}8 \times 0.25 \\
\mathrm{~mm}\end{array}$ & $\begin{array}{c}8 \times 0.25 \\
\mathrm{~mm}\end{array}$ & $\begin{array}{c}8 \times 0.25 \\
\mathrm{~mm}\end{array}$ \\
\hline Injection shape & Std & $5 \%$ pre & $10 \%$ pre & Std & $5 \%$ pre & $10 \%$ pre \\
\hline Pilot timing, ATDCF & $\mathrm{N} / \mathrm{A}$ & -13 & -13 & $\mathrm{~N} / \mathrm{A}$ & -13 & -14 \\
\hline Pilot duration, $\mathrm{ms}$ & N/A & 0.256 & 0.42 & N/A & 0.256 & 0.426 \\
\hline Main timing, ATDCF & -7 & -4.75 & -4.3 & -7 & -6.35 & -5.25 \\
\hline Main duration, $\mathrm{ms}$ & 2.93 & 2.756 & 2.68 & 2.79 & 2.656 & 2.722 \\
\hline
\end{tabular}
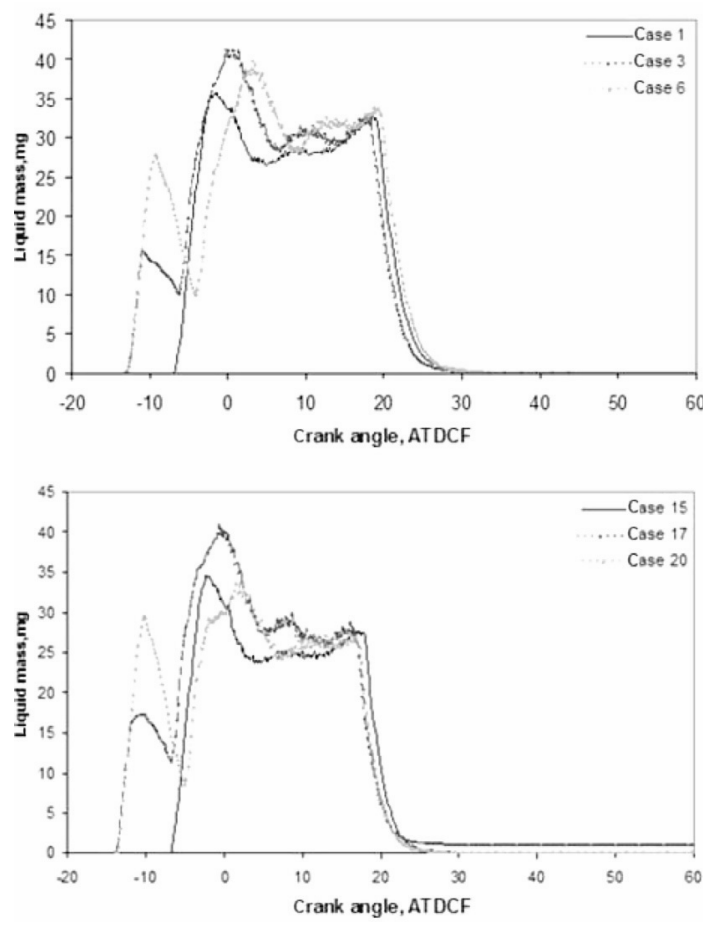

Figure 5

In-cylinder liquid fuel mass vs time.
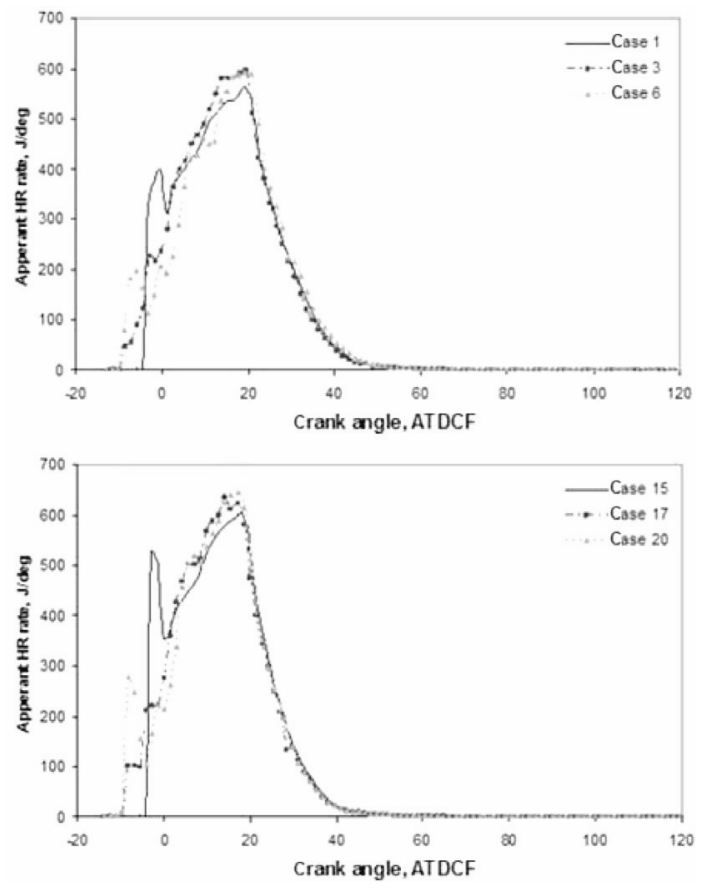

Figure 6

Apparent heat release rate $v s$ time. the start of diffusion burning. It should be noted that the injection timing and needle lift at the start of injection are selected so that the second peak of heat release becomes higher than the first one due to decrease of $\mathrm{NO}_{x}$ amount.

Since the mixing before start of combustion in set 2 is better than set 1 , more pre-mixed combustion will be happened in set 2. This improvement in mixing of air and fuel results from improvement in discharge coefficient as well as shortening injection duration in order to deliver the same amount of fuel. It is expected that the $\mathrm{NO}_{x}$ amount in set 2 of results will be more than set 1 of them. Figure 7 shows the cylinder pressure diagram for set 1 and 2 of results. As shown in these diagrams, pre-injection could eliminate the high rate of pressure rise due to premix combustion. Also cylinder temperature for set 1 and 2 of results is shown in Figure 8.

As shown in these diagrams, the maximum temperature of the cylinder with 8 holes injector has not the same trend (pre-injection $v s$ standard type) as 6 holes type. This should be resulted from different start of injection for pre-injection type in these two types of injectors. But the maximum cylinder temperature with set 2 is higher than set 1 while the location of maximum temperature is nearly the same. This issue results higher $\mathrm{NO}_{x}$ amount in 8 holes nozzle configuration. Figure 9 shows the in-cylinder $\mathrm{NO}_{x}$ amount versus crank angle. These diagrams show that the $\mathrm{NO}_{x}$ amount in the cylinder for set 1 of results will decrease with pre-injection because the high rate of pre-mixed combustion has been eliminated and the maximum temperature 

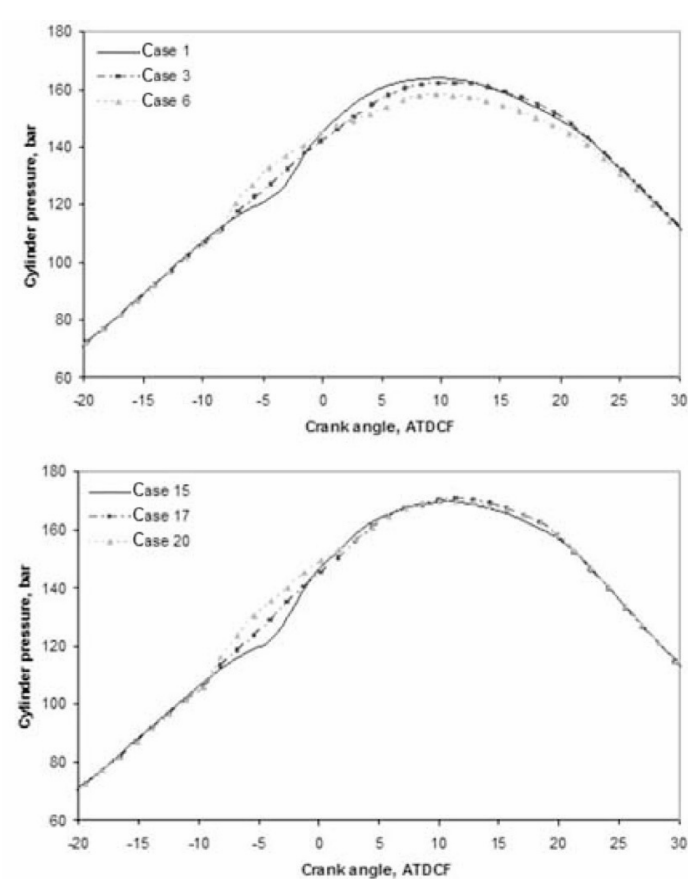

Figure 7

In-cylinder pressure $v s$ crank angle.
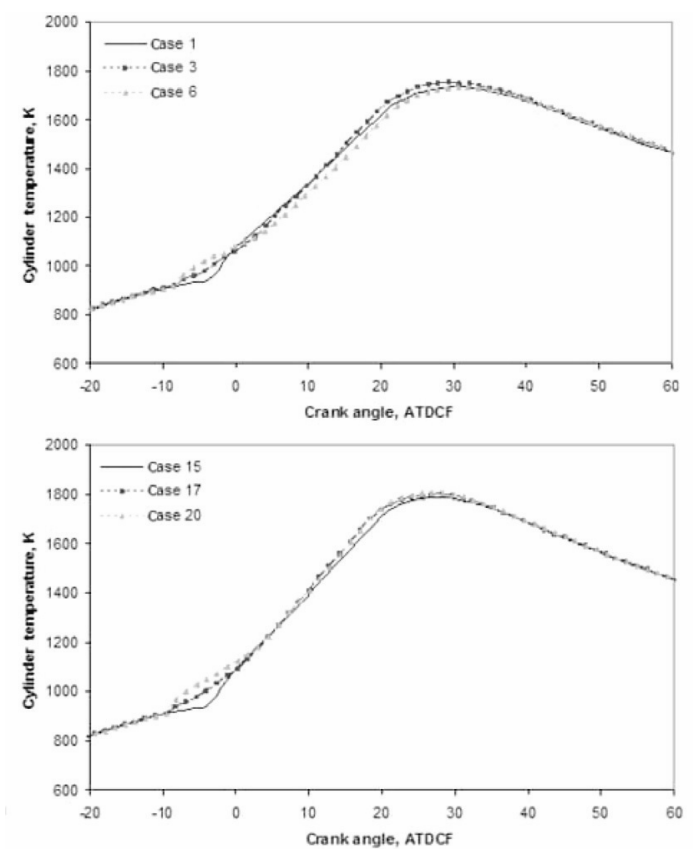

Figure 8

In-cylinder temperature $v s$ crank angle.

has been decreased at the same crank angle. In the second set of the results, the $\mathrm{NO}_{x}$ amount is higher than the first set; this is because of shorter injection duration due to decrease of nozzle hole diameter. Figure 10 also show
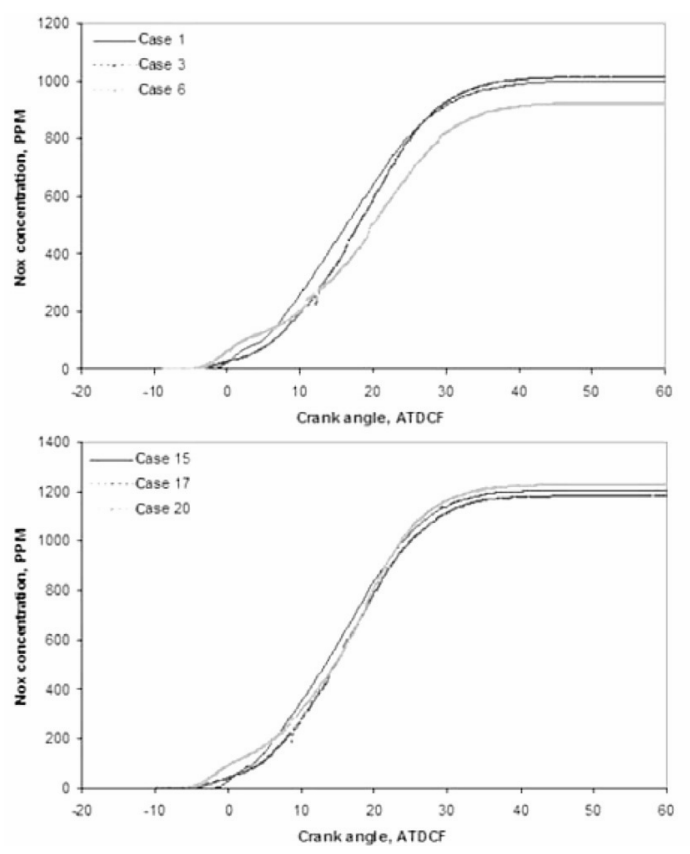

Figure 9

In-cylinder $\mathrm{NO}_{x}$ amount $v s$ crank angle.

the soot concentration in semi logarithmic diagram. This shows that the soot concentration will not be affected with adjusting the start of injection.

\subsection{B: Engine Performance Results}

Figure 11 shows the engine performance and emission results for selected simulation cases. The simultaneous decrease in amount of $\mathrm{NO}_{x}$ and Soot, has been resulted in some cases, is because of using Pre-injection system which is decrease the rate of pre-mixed combustion and $\mathrm{NO}_{x}$ amount.

Depending on the extent of $\mathrm{NO}_{x}$ reduction, an earlier injection and combustion start is possible, resulting in an increase of thermal efficiency. These data show that all pre-injection cases could be used to achieve BSFC (Brake Specific Fuel Consumption) of 199 g/kWh without any significant retarding of main injection timing. But if the duration of injection in standard cases is revised, it can be used to achieve BSFC of $199 \mathrm{~g} / \mathrm{kWh}$ without any significant retarding of standard injection.

So, the case $25,7 \times 0.27 \mathrm{~mm}$ with $10 \%$ pre-injected fuel, and case $10,7 \times 0.27 \mathrm{~mm}$ with $5 \%$ pre-injected fuel, with the dwell time of 0.55 milliseconds are the best points in terms of emission and fuel economy.

\section{CONCLUSION}

Regarding to all simplifications which are implemented to multi-zone model and respect to the target of this study for 

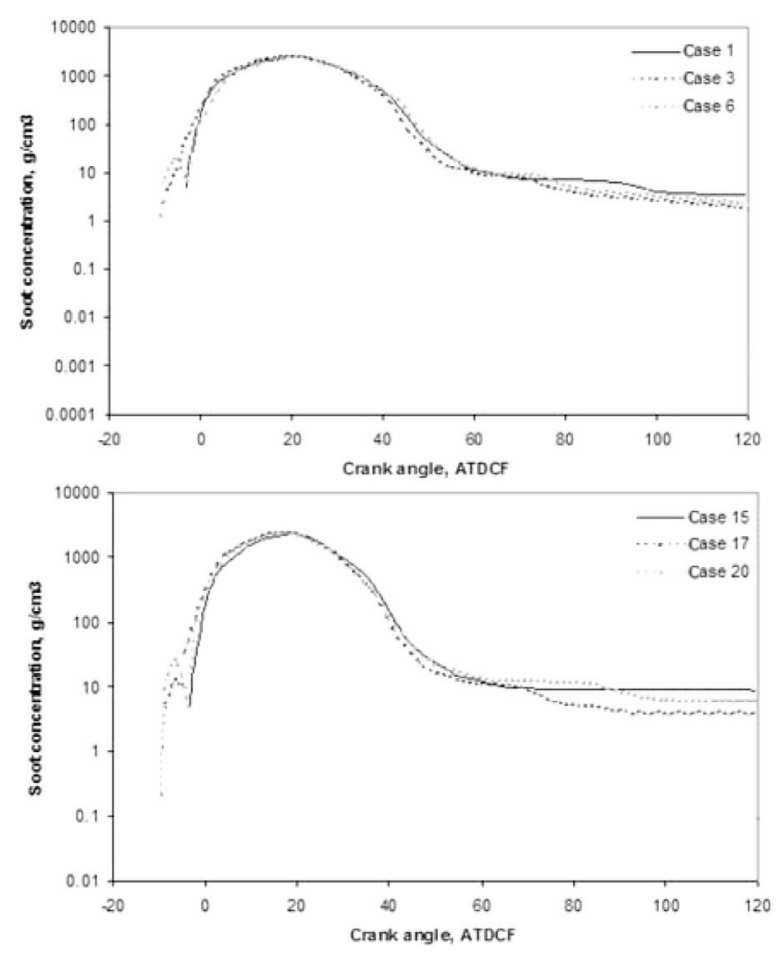

Figure 10

In-cylinder soot concentration $v s$ crank angle.

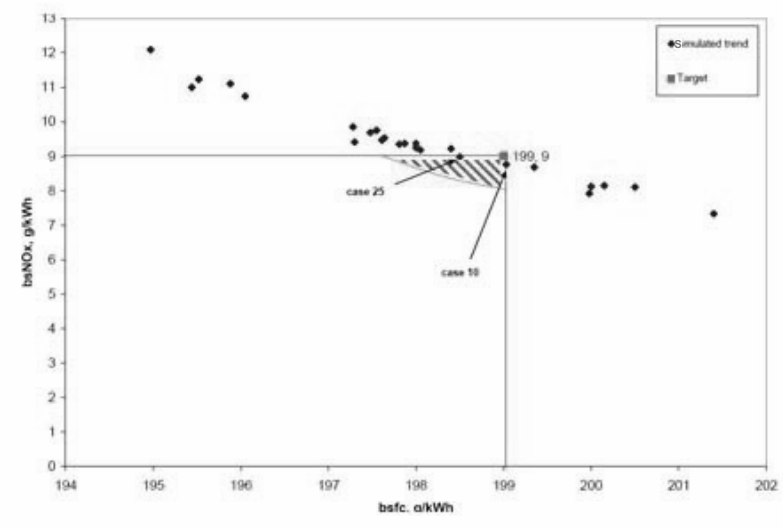

Figure 11

BSFC and $\mathrm{NO}_{x}$ trade-off with recommended points.

finding the high efficiency and low $\mathrm{NO}_{x}$.engine concept, the following summarized result will be achieved:

- The results of multi-zone model have a good agreement with experiment and could be used in new engine development process with acceptable level of reliability and confidence;

- The major advantage of pre-injection is reducing of the amount of fuel-air mixture just before start of combustion. This issue makes the mixture formation to be done step by step during injection; therefore it avoids the large premix heat release at the first phase of combustion;

- The targets for BSFC and $\mathrm{NO}_{x}$ amount in order to have the high efficiency and low $\mathrm{NO}_{x}$ engine concept could be achieved using pre-injection without retarding main injection timing and increase of smoke amount;

- It is suggested that in order to find better results for optimum points, the multi objective optimization will be carried out with generic algorithm.

Also, the amount of $\mathrm{NO}_{x}$ will be decreased using an additional system such as EGR, SCR catalyst, water injection, ... by adding such systems to the engine, the exhaust $\mathrm{NO}_{x}$ emission will decrease more without increasing a significant amount in engine BSFC.

\section{ACKNOWLEDGEMENTS}

The authors wish to extend their thanks and gratitude to DESA of Iran for its support this study and also allowing using its development and client in-service engine data applied for the validation and verifications of simulated model.

\section{REFERENCES}

1 Hlousek J., Bernhaupt M., Kogler B. (2001) Electronically controlled injection rate shaping for medium speed diesel engines, 23th CIMAC Congress, Hamburg.

2 Hlousek J. (2004) Common rail system for large diesel engines 24th CIMAC Congress, Kyoto.

3 Hiroyasu H., Kadota T., Arai M. (1983) Development and Use of a Spray Combustion Modeling to Predict Diesel Engine Efficiency and Pollutant Emissions (part 1: Combustion Modeling), B. JSME, 26.

4 Jung D., Assanis D. (2001) Multi-Zone DI Diesel Spray Combustion Model for Cycle Simulation Studies of Engine Performance and Emissions, SAE paper 2001-01-1246.

5 Heywood J.B. (1988) Internal Combustion Engines Fundamentals, McGraw Hill, 3rd ed.

6 Reitz R.D., Bracco F.V. (1979) On the Dependence of Spray Angle and Other Spray Parameters on Nozzle Design and Operating Conditions, SAE paper 790494.

7 Hiroyasu H., Arai M., Tabata T. (1989) Empirical Equations for the Sauter Mean Diameter of a Diesel Spray, SAE paper 890464.

8 Ranz W.E., Marshall W.R. (1952) Evaporation from drops, Chem. Eng. Prog. 48, 57-72.

9 Ramos J.I. (1989) Internal combustion engine modeling, Hemisphere publishing corporation.

Final manuscript received in July 2009 Published online in January 2010 